\title{
Wave parameter classification based on morphological changes around a small wave-dominated tidal-inlet using a schematized Delft3D model
}

\author{
Shaeri, S. ${ }^{\text {a }}$ Nguyen, A.H. ${ }^{\text {a }}$ and Strauss, D. ${ }^{\text {a }}$ \\ ${ }^{a}$ Griffith Centre for Coastal Management, Griffith University, Gold Coast Campus, Australia \\ Email: saeed.shaeri@griffithuni.edu.au
}

\begin{abstract}
The investigation of long-term morphological changes of a tidal-inlet using process-based models is a complicated and resource dependant task. To date, a number of input reduction techniques have been utilised to reduce the complexity of the modelling tasks; amongst them the wave condition has been shown to be of significant importance. Rapid and significant morphological changes generally occur as a result of a highly energetic waves occurring over a short period, whilst low energy waves can only be influential if they occur for a longer period. Therefore, research has been focused on methods to categorize a continuous time-series of waves into discrete events which, in combination, have an almost identical morphological outcome as the full time-series. Nevertheless, there is no clear agreement on a preferred categorization method based on an overall frequency of occurrence of wave parameters. Additionally, for a re-arranged, categorized wave dataset, the selected chronology of the events is a matter of further consideration as research has shown that the morphological outcome would vary. Moreover, despite some noteworthy research for coastal areas, the current literature is quite limited in regard to morphological changes around small tidal-inlet entrances. The first of the above-mentioned gaps was considered in this study and as such this article aims solely to determine important classes of wave parameters based on their relative morphological impacts on a wave-dominated, small tidal-inlet entrance. The effects of chronology, as well as the cumulative influence of consecutive wave events are therefore not further considered here.
\end{abstract}

For this study several categorization methods from the literature were investigated. The selected approach uses an offshore directional wave time-series to statistically classify wave parameters. Wave data is initially separated by wave period (e.g. Tp), to distinguish between seas and swell waves. Then, based on the frequency of the occurrence of particular wave height and direction ranges, data is classified into sub-groups. Later, the sub-groups with the combined total frequency percentage of occurrence of about $90 \%$ are identified to encompass the required classes of schematized wave parameters for modelling. The remaining sub-groups (i.e. with total $10 \%$ occurrence) are considered to be morphologically ineffective. Furthermore, for preparing the model boundary data, there needs to be representative wave parameters for each of the selected classes. For the representative wave direction and period, a simple algebraic average of data for each class could be used. However, the best practice to find the representative average wave height could be through averaging the energy of individual incident waves for each of the classes. All these classified parameters then are used as input for morphological model.

For the case study of this research, the wave classification procedure resulted in 20 classes of wave data. An existing, calibrated, validated, coupled Delft3d Wave and Flow model was used along with a simple harmonic tide at the boundary, to perform the necessary morphological modellings. In this research, the inlet entrance, its channel and the flood shoal of the selected case study area were the main focus. The modelling results showed that the wave classes which have undergone less refraction (i.e. cases with shore-normal offshore wave direction) were more prominent in transport of sediment all around the inlet entrance; irrespective of the wave height and period. Conversely, waves with a more oblique angle of incidence showed less transport in to the inlet inner lagoon; even for very large wave heights. The influence of wave period was also shown to be noticeable, as extensive erosion/accretion events based on larger wavelength of swell in comparison to sea waves was existent. The variation of depth averaged velocity, erosion/accretion and wave parameters at selected locations revealed that locations inside the inlet lagoon and at the entrance channel were less sensitive to different wave conditions. In contrast, the observation point offshore of the entrance, directly followed the changes to wave parameters. By having an insight in to the importance of each individual class of wave data, the classification procedure could be re-assured. Moreover, a particular wave class could be statically important but morphologically ineffective. Therefore, the output could assist in selection of an appropriate chronology for a cumulative morphological study.

Keywords: Wave schematization, sediment transport, Delft3D, tidal inlet 


\section{INTRODUCTION}

An integral part of current coastal engineering design is the study of sediment transport. This is more pronounced in cases where the areas of interest have a high natural sediment flux and a natural or manmade obstruction in the passage of sediment flux. Such obstruction influences the transported sediment and may cause significant immediate local effects. The other influencing aspect is the existence of coastal inlets which may act as sediments' sources, stores or sinks by that seasonally affect sediment transport. Increasingly, the study of coastal processes is conducted using modelling software packages. However, limitations exist in regard to the capacity of computers to process large input databases and perform long temporal simulations of complex processes at high resolutions. To overcome this issue, the so called 'input reduction techniques' along with process-based modelling techniques are widely used (Latteux, 1995; Lesser et al., 2004) through rearranging the input parameters and generating representatives of the actual/full dataset.

This research is part of a main project which aims to investigate the sediment transport patterns around a small, wave-dominated, tidal inlet. The inlet's back-barrier estuary is subjected to annual dredging which significantly changes the sediment balance in a larger area than itself. As a result, an appropriate dredging management programme is required to satisfy a wide range of stakeholders. Due to highly seasonal climate variations, there is a wide range of waves affecting the local sediment transport and the inlet entrance morphology. However, currently available resources do not provide a direct and viable tool to perform thorough numerical simulations. Therefore, in addition to the abovementioned input reduction techniques, in order to achieve a less resource demanding modelling, this research is designed to test the significance of each of the selected wave parameters (i.e. wave height, direction and period or in combination) on the sediment transport. Subsequently, critically important ranges for the wave parameters in regard to the extent of morphological changes are identified to be used for the required modelling of the main project. Therefore, overall, the study has two parts: first to identify morphologically significant discrete classes of wave parameters, and then to perform desired morphological modelling based on an appropriate chronology of the selected, schematized wave classes. The latter is not presented in this article.

\section{WAVE CLASSIFICATION}

Considering the methods proposed by Dastgheib et al. (2012) and Roelvink and Walstra (2004), the following schematization method was adopted for wave classification. An available offshore directional wave time-series, is statistically analysed to derive classes of wave parameters. First the dataset is divided in two sub-sets of wave type based on their peak wave period $\left(T_{P}\right)$ to distinguish between seas and swell waves. Then using wave height bins of $0.5 \mathrm{~m}$ and standard geographical directions the frequency occurrence of each group of specific wave height and direction is calculated for each of the two wave types. From this table, the cells which have the largest occurrence $(90 \%$ in total) are selected. In this way, the selected data are considered to be morphologically influential for a comprehensive modelling. Additionally, this means that the remaining $10 \%$ of the original dataset (say 36 days of a typical year) which is not included in the selection, is considered individually insignificant.

Consequently, for the purpose of input reduction and using the selected records as input boundary data, there needs to be representative parameters for each of the selected groups. Accordingly, for the representative wave direction and period, a simple algebraic average of data for each class could be used. However, to find the representative wave height, the method used by Dastgheib et al. (2012) was adopted. Based on their method, for each of the wave records, the wave energy is calculated. Then, the average of the wave energies for each of the abovementioned groups along with their relevant average period are used to re-calculate wave height. Such a wave height is deemed to be a better morphological representative of a series of records rather than a simple algebraic average. In the end, there remain a few classes of wave parameters, identified by a unique combination of wave height, direction and period, which are used as boundary conditions for separate morphological modelling.

\section{STUDY AREA AND MODEL PREPARATION}

Currumbin Creek is a small, highly popular tidal inlet located in southeast Queensland, Australia $\left(28.127^{\circ} \mathrm{S}\right.$, $153.484^{\circ}$ E-Figure 1) which has undergone a long history of construction, maintenance and dredging. For the past 30 years, there has been a dredging campaign in place to either stabilize the entrance or to keep the entrance open. Safe navigation, lessening the risk of up-estuary inundation and appropriate water quality in the creek are the main factors impelling the dredging operation. To provide supportive information for the design of Currumbin Creek's annual dredging, a comprehensive project has been introduced. This study therefore, aimed to establish a better insight into the effect of a highly variable wave climate on the amount 
of sediment transport and the pattern of morphological changes. The inlet is bounded by two jetties and a 20 hectare back-barrier lagoon is situated at the downstream part of the $24 \mathrm{~km}$ long river, with a morphologically insignificant water and sediment discharge (Shaeri et al.,2014). The main project objective is to build a comprehensive hydro-sedimentological model of the Currumbin entrance and its surrounding beaches (Shaeri, 2015). For that research, wave and tide input reduction methods have been tested to decrease the modelling time and the amount of output data. However, to test the accuracy of the adopted methods, it was deemed necessary to investigate the sole effect of wave characteristics on the output parameters regardless of their chronological sequence.

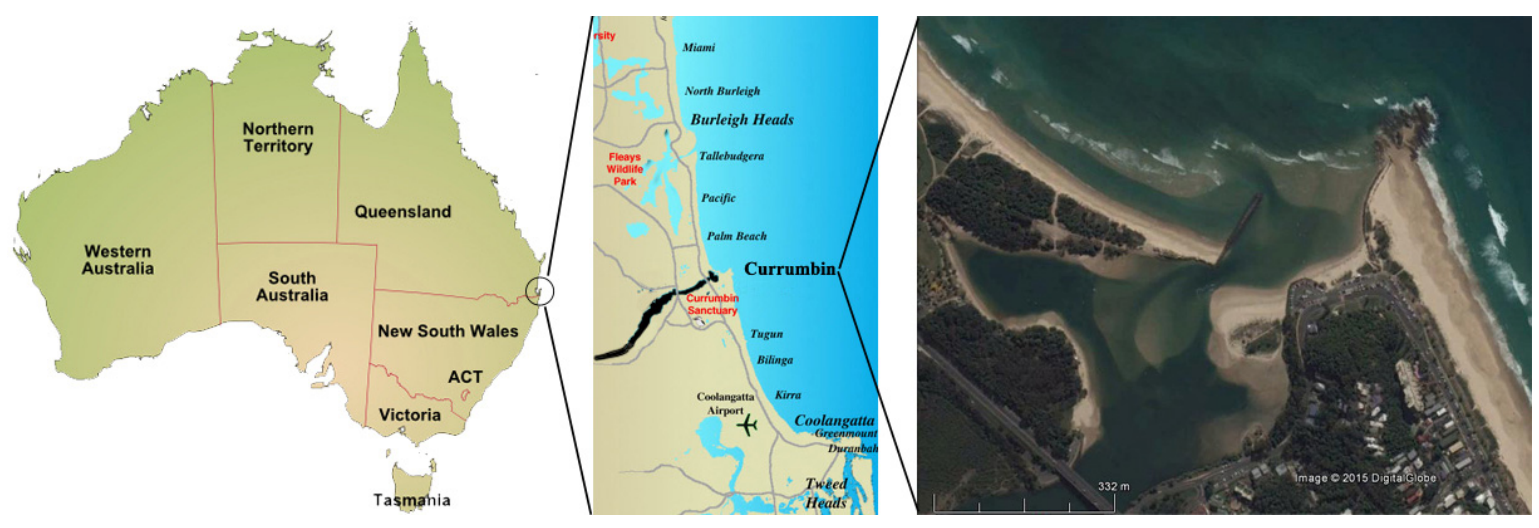

Figure 1. Map (Shaeri et al., 2013) and aerial photo of the area (current in April 2015, adopted from GoogleEarth).

Shaeri's (2015) calibrated hydrodynamic and wave model (Delft3D FLOW and WAVE) were used for this study (Figure 2). The alongshore and cross shore dimension of the domain is about $5 \times 2 \mathrm{~km}$. For computational efficiency, only seven kilometres of the down-estuary is included in the hydrodynamic model. The largest and smallest (in the middle of the entrance channel) grid sizes are $30 \times 25 \mathrm{~m}^{2}$ and $15 \times 20 \mathrm{~m}^{2}$, respectively. A 19-year astronomical tidal data was schematized in to a synthetic harmonic tide, to be used for flow boundary condition. The Chezy roughness formula was used with the horizontal eddy viscosity and diffusivity of 1 and $10 \mathrm{~m}^{2} / \mathrm{s}$, respectively. A constant directional spreading (cosine power) of 5 was chosen. Due to the approximately even distribution of sediment characteristics around the area (Howorth et al., 2014), only one sediment fraction was used with the specific density of $2650 \mathrm{~kg} / \mathrm{m}^{3}$ and median sediment diameter $\left(\mathrm{D}_{50}\right)$ of $285 \mu \mathrm{m}$.

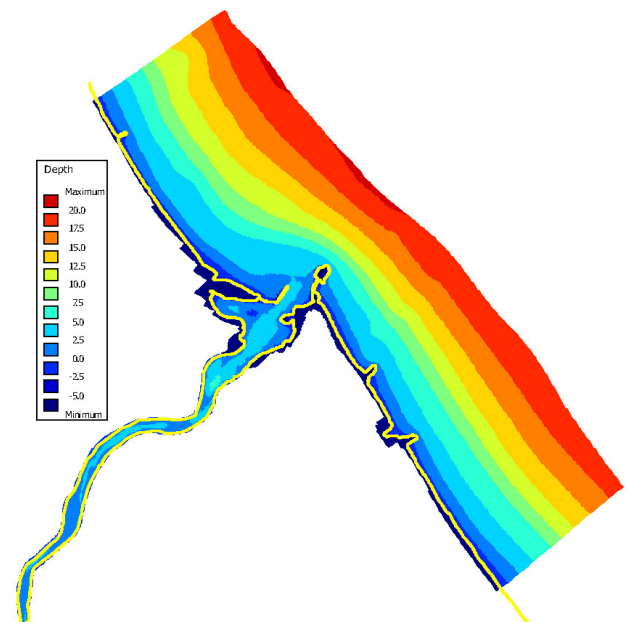

Figure 2. The extent of FLOW model.

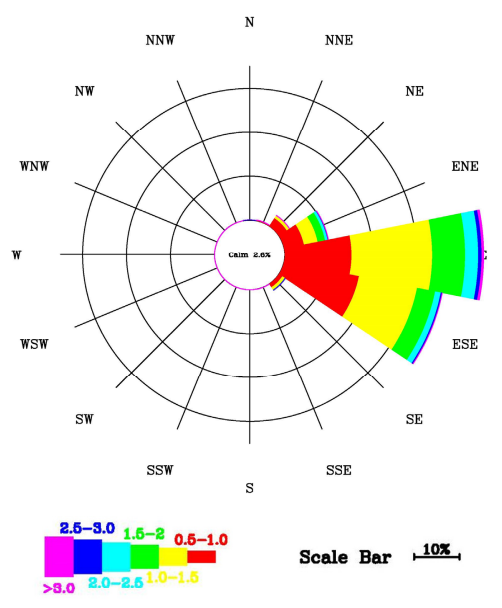

Figure 3. 11-year wave rose at a location offshore to the entrance in $6.0 \mathrm{~m}$ water depth (ref. LAT).

Later, the output of Shaeri's (2015) global WAVE model (an 11-year local, wave data) was used to obtain boundary input data; depicted by the wave rose in Figure 3. Significant wave heights were clustered in bins of $0.5 \mathrm{~m}$ and the peak wave directions were grouped based on standard geographical directions (i.e. N, NNE, $\mathrm{NE}$, etc.). Moreover, to investigate the influence of wave periods, the peak period of 10s was used as the classification threshold to distinguish between seas and swell type wave conditions, slightly higher than Hemer and Griffin's (2010) suggestion of 9s. Then, the frequency of occurrence of each of the significant 
Shaeri et al., Wave parameter classification ... around a small ... tidal-inlet using a ... Delft3D model

wave height and direction groups was calculated based on the number of wave records in each of the categories (Table 1). The 20 cases that made up about $90 \%$ of the total wave occurrence (Table 2 ) were used to perform the necessary morphological modelling for a period of two days with a morphological factor of four (Lesser et al., 2004) to observe the inlet changes. This period is deemed long enough for very high energy wave classes as they usually occur over a shorter period than more frequent lower energy waves.

\section{RESULTS AND DISCUSSION}

The results of the modelling of all 20 wave cases are presented in this section. This includes individual point outputs for important locations (shown in Figure 4) as well as 2D maps of the sediment erosion or accretion (Figures 5-6). Model output locations were chosen updrift and downdrift of jetties, in the entrance and channel mid-points and in the flood shoal area. At these points, the maximum depth-averaged velocity, the maximum erosion or accretion and the wave height and direction are compared (Figure 7). Moreover, considering Table 2, a series of possible comparison sets are considered (Table 3 ) to investigate the relative effect of individual wave parameters. The comparisons are classified into five groups, comprising cases with either the same wave height range ( $\mathrm{H}$ sets in Table 3 )

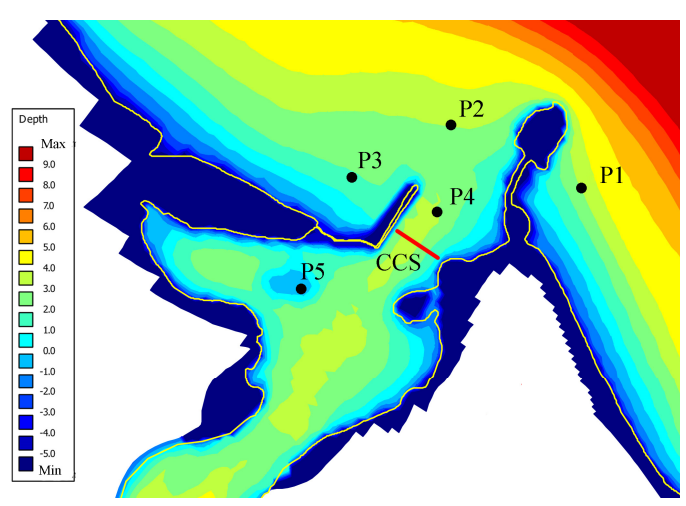

Figure 4. Location of output points on the bathymetry map. or the same wave direction (D sets), as well as cases with simultaneous same wave height and period (HT sets), same wave direction and period (DT sets) or same wave height and wave direction (HD sets).

Table 1. Percentage of the frequency occurrence of the wave characteristics based on the 11-year dataset.

\begin{tabular}{|c|c|c|c|c|c||c|c|c|c|c|}
\cline { 2 - 12 } \multicolumn{1}{c|}{} & \multicolumn{9}{c||}{ Sea-type waves } & \multicolumn{7}{c|}{ Hs range (m) } \\
\cline { 2 - 12 } \multicolumn{1}{c|}{} & \multicolumn{9}{|c|}{ Swell-type waves } \\
\hline Dir. & $<0.5$ & $0.5-1.0$ & $1.0-1.5$ & $1.5-2$ & $2.0-2.5$ & $<0.5$ & $0.5-1.0$ & $1.0-1.5$ & $1.5-2$ & $2.0-2.5$ \\
\hline NNE & - & $1.2 \%$ & - & - & - & - & - & - & - & - \\
\hline NE & - & $2.5 \%$ & $0.7 \%$ & - & - & - & - & - & - & - \\
\hline ENE & - & $8.4 \%$ & $8.6 \%$ & $3.7 \%$ & $1.1 \%$ & - & $1.2 \%$ & $2.5 \%$ & $1.6 \%$ & $1.0 \%$ \\
\hline E & - & $8.7 \%$ & $10.1 \%$ & $3.4 \%$ & $1.2 \%$ & $1.1 \%$ & $10.4 \%$ & $9.1 \%$ & $3.5 \%$ & $1.2 \%$ \\
\hline ESE & - & $3.0 \%$ & $2.0 \%$ & $0.6 \%$ & - & - & $4.8 \%$ & $2.8 \%$ & $0.6 \%$ & - \\
\hline
\end{tabular}

Table 2. The 20 selected wave cases.

\begin{tabular}{|c|c|c|c||c|c|c|c|}
\hline \multicolumn{9}{|c||}{ Sea-Type waves } & \multicolumn{4}{c|}{ Swell-type waves } \\
\hline Case & Hs (m) & Direction & Tp (s) & Case & Hs (m) & Direction & Tp (s) \\
\hline 1 & 0.7 & NNE & 5.2 & 12 & 0.9 & ENE & 11.5 \\
\hline 2 & 0.8 & NE & 6.1 & 13 & 0.7 & E & 11.9 \\
\hline 3 & 0.9 & ENE & 7.7 & 14 & 0.8 & ESE & 11.7 \\
\hline 4 & 0.9 & E & 8.3 & 15 & 1.0 & ENE & 11.5 \\
\hline 5 & 0.7 & ESE & 8.3 & 16 & 1.2 & E & 12.0 \\
\hline 6 & 1.2 & ENE & 8.2 & 17 & 1.0 & ESE & 11.8 \\
\hline 7 & 1.2 & E & 8.2 & 18 & 1.5 & ENE & 11.5 \\
\hline 8 & 1.2 & ESE & 8.1 & 19 & 1.9 & E & 12.0 \\
\hline 9 & 2.2 & ENE & 8.4 & 20 & 2.0 & E & 12.0 \\
\hline 10 & 1.7 & E & 8.4 & & & & \\
\hline 11 & 1.9 & E & 8.7 & & & & \\
\hline
\end{tabular}

The outputs show that for set H1 (Figure 5, cases 1-5), the wave height boundary condition at the east boundary is the lowest of all cases. Therefore, it was expected that the least amount of erosion/accretion would be observed at each of the selected locations (Figure 4). However, the difference in the incident wave direction creates a wide range of different sedimentation patterns (Figure 5, $6 \&$ 7). The second significant accretion $(+0.4 \mathrm{~m}$ at $\mathrm{P} 4)$ is case 4 with an $\mathrm{E}$ wave direction incident at the boundary (See Figure 7 for these types of data). As for $\mathrm{H} 1$, set $\mathrm{H} 2$ shows the highest accretion in cases 6 and $7(+0.9$ and $+0.8 \mathrm{~m}$ respectively at P4). Markedly, the significant wave heights obtained at P4 for these cases (between 0.52 to $0.67 \mathrm{~m}$ ) were the 

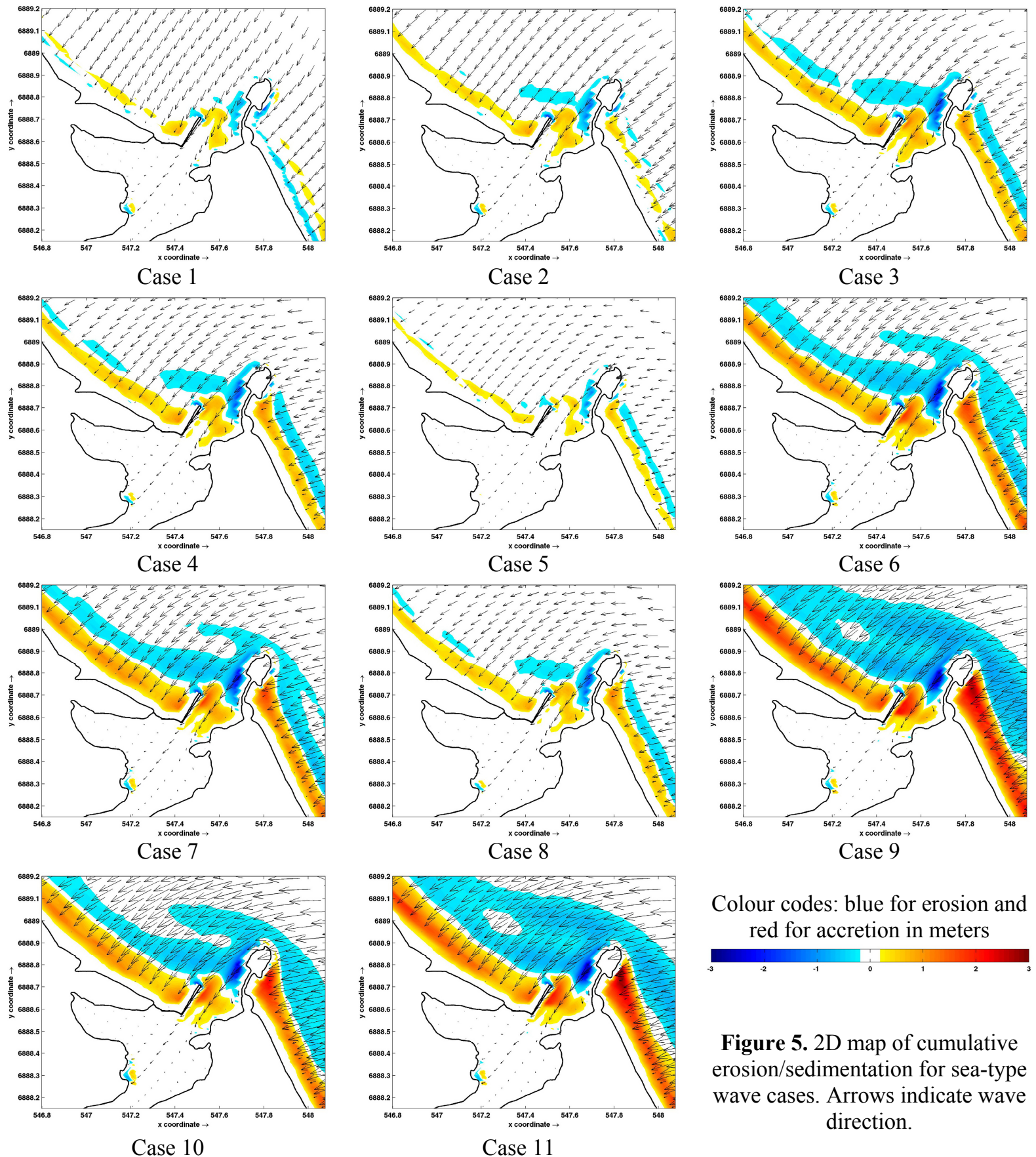

Colour codes: blue for erosion and red for accretion in meters

Figure 5. 2D map of cumulative erosion/sedimentation for sea-type wave cases. Arrows indicate wave direction.

Table 3. Sets of selected cases for comparison.

\begin{tabular}{|c|c|c|c|c|c|}
\hline Comparison Type & $\begin{array}{c}\text { Same wave } \\
\text { height }\end{array}$ & Same direction & $\begin{array}{c}\text { Same wave } \\
\text { height and } \\
\text { period }\end{array}$ & $\begin{array}{l}\text { Same direction } \\
\text { and period }\end{array}$ & $\begin{array}{c}\text { Same wave } \\
\text { height and } \\
\text { direction }\end{array}$ \\
\hline $\begin{array}{l}\text { Relevant cases (as } \\
\text { per Table 2) for } \\
\text { each comparison } \\
\text { set }\end{array}$ & $\begin{array}{l}\text { H1: } 1,2,3,4 \& 5 \\
\text { H2: } 6,7 \& 8 \\
\text { H3: } 9 \& 10 \\
\text { H4: } 12,13 \& 14 \\
\text { H5: } 15,16 \& 17 \\
\text { H6: } 18 \& 19\end{array}$ & $\begin{array}{l}\text { D1: } 3,6 \& 9 \\
\text { D2: } 4,7,10 \& 11 \\
\text { D3: } 5 \& 8 \\
\text { D4: } 12,15 \& 18 \\
\text { D5: } 13,16,19 \& 20 \\
\text { D6: } 14 \& 17\end{array}$ & $\begin{array}{l}\text { HT1: } 6 \text { \& } 7 \\
\text { HT2: } 4 \text { \& } 5 \\
\text { HT3: } 9 \& 10\end{array}$ & $\begin{array}{l}\text { DT1: } 12,15 \& 18 \\
\text { DT2: } 16,19 \& 20\end{array}$ & $\begin{array}{l}\text { HD1: } 3 \& 12 \\
\text { HD2: } 6 \& 15 \\
\text { HD3: } 9 \& 18 \\
\text { HD4: } 4 \& 13 \\
\text { HD5: } 7 \& 16 \\
\text { HD6: } 10 \& 19 \\
\text { HD7: } 11 \& 20 \\
\text { HD8: } 5 \& 14 \\
\text { HD9: } 8 \& 17\end{array}$ \\
\hline
\end{tabular}



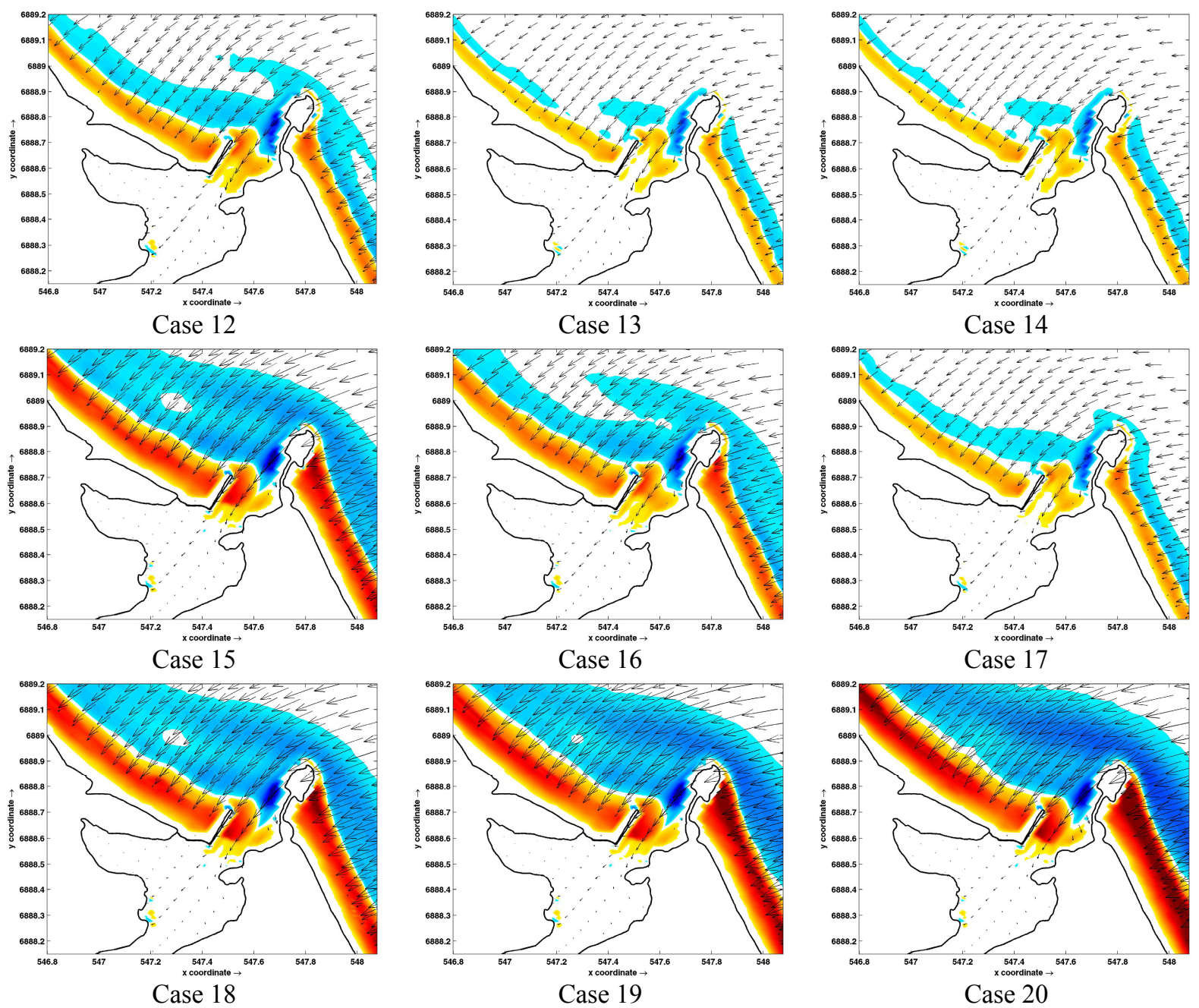

Figure 6. 2D map of cumulative erosion/sedimentation for swell-type wave cases. Arrows indicate wave direction. See Figure 5 for the legend.

highest amongst the cases in sets $\mathrm{H} 1$ and $\mathrm{H} 2$. In set $\mathrm{H} 3$, case 9 with an ENE incident wave direction, again shows a higher accretion $(+1.5 \mathrm{~m}$ at P4) compared to case $10(+0.9 \mathrm{~m}$ at P4). Notably, for these two cases compared with the others in sets $\mathrm{H} 1$ to $\mathrm{H} 3$, the extent of accretion was significantly large $(+0.4$ to $1.5 \mathrm{~m})$, even causing accretion at $\mathrm{P} 1$. When considering the comparison of swell-type cases, almost the same results as reported above were achieved. For instance, in set H4, once more the ENE wave direction (case 12) shows larger accretion at $\mathrm{P} 4$ than the others $(+0.8 \mathrm{~m}$ compared with $+0.1-0.2 \mathrm{~m})$. For this case, there is also the highest erosion at P1 (-0.8m). These similar results show the importance of incident waves from the ENE and E directions. Additionally, by comparing the D sets of results, an obvious conclusion is achieved; that is, the higher the wave height, the more significant the erosion/accretion.

In order to better investigate the importance of the ENE incident wave conditions at the boundary, HT sets were used. In cases 6 and 7 with the same incident wave heights and periods, the result for the ENE wave direction shows a slightly higher accretion than the E wave direction at all points. In cases 9 and 10, this difference is even more profound; whereas it is insignificant for cases 4 and 5. Considering the DT sets, and interestingly for cases 15 and 18 in DT2 which have an ENE incident wave direction, the amount of erosion/accretion at all points (except at P1) is almost the same, although there is a $0.5 \mathrm{~m}$ difference in the mean significant wave heights. The last series of comparisons is for the HD sets where the difference between sea and swell-type waves is explored. In all sets, the swell-type cases show a significantly larger erosion/accretion in all locations, although the wave heights in all the selected locations are comparably identical (with a few exceptions). This shows that regardless of the wave period, the nearshore wave heights are almost the same for the same wave height conditions at the boundary.

An overall comparison of the cases is achieved through the interesting summary graphs of Figure 7, which are depicted by looking at the overall variation of the cumulative accretion/sedimentation and maximum 
depth averaged velocity, in five selected locations. For instance, Figure 7-a shows erosion at P2 in all cases, while there is negligible change at P5. Additionally, for less than $1.5 \mathrm{~m}$ significant wave height at the boundary, regardless of wave direction, there is down to $-0.8 \mathrm{~m}$ erosion and up to $0.4 \mathrm{~m} / \mathrm{s}$ velocity at P1; whereas for larger swell waves, there is over $2.0 \mathrm{~m}$ of accretion and $1.4 \mathrm{~m} / \mathrm{s}$ of velocity. As discussed, except for ENE and E directions, the amount of accretion at P4 is less than $0.5 \mathrm{~m}$ for all the cases. While the velocity magnitudes at P2 do not reach such a maximum (up to $0.4 \mathrm{~m} / \mathrm{s}$ ), the velocity magnitudes at P3 are comparably strong for many of the cases. Nevertheless, there is a narrow range of velocity magnitudes observed at P4 for all the different wave conditions.
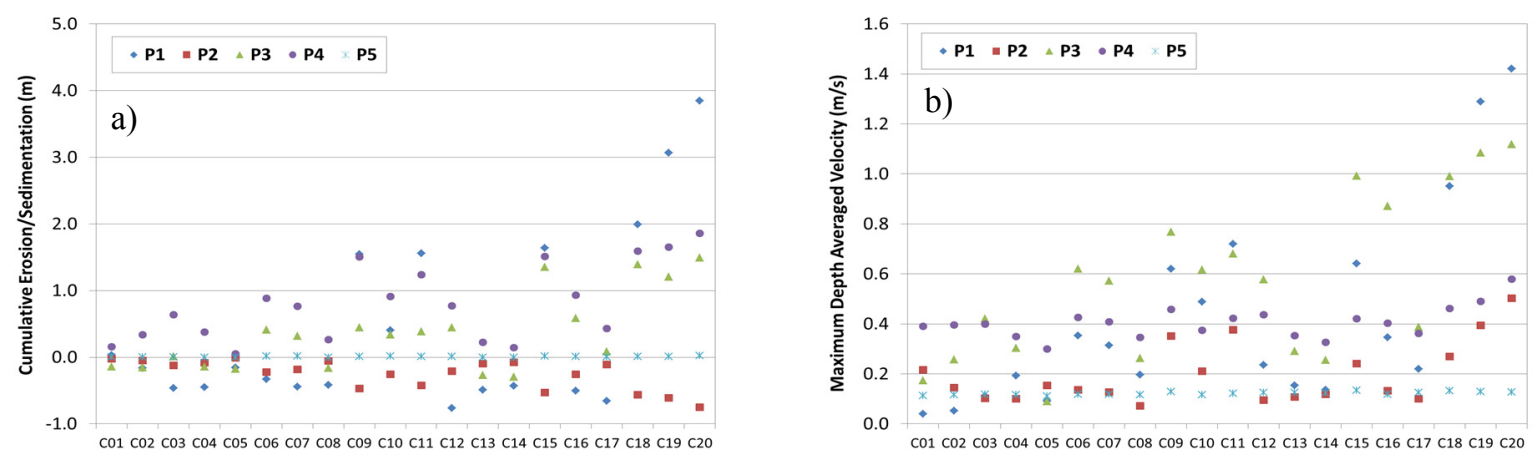

Figure 7. Summary of outputs in selected locations (Ref. to Figure 4);

a) Cumulative erosion/sedimentation $(\mathrm{m})$, b) Maximum depth-averaged velocity $(\mathrm{m} / \mathrm{s})$.

\section{CONCLUSION}

In recent process-based morphological modelling, input reduction techniques play an important part in obtaining the desired outcome with reduced complexity and computational demand. One of aspects of these techniques, i.e. wave schematization and classification, is considered here in this research in order to derive a simple, robust approach for morphological investigation of small tidal inlets. The accretion and thus sedimentation of the entrance channel are shown to be influenced by wave direction (more so than by wave height or wave period). There is also a propensity for the greatest infilling during shore-normal incident waves, which is then exacerbated by increases in wave height. Wave refraction around the inlet entrance, for more shore-parallel, oblique wave directions results in lower wave energy in the entrance; thus reduced infilling for comparable offshore wave heights. These findings have implications for management strategies in view of future variations to wave climate that may occur on a seasonal, inter-annual or longer term time scales. For instance, in the location of this research case study, an increasingly ENE wave climate (such as those experienced during La Nina) may transport more sediment into the inlet and require more frequent or larger volumes of dredging than the present typically ESE dominated wave climate (El Nino or neutral).

\section{REFERENCES}

Callaghan, J. \& Power, S. B. (2011), Variability and Decline in the Number of Severe Tropical Cyclones Making Land-Fall over Eastern Australia since the Late Nineteenth Century, Climate Dynamics, 37(3), 647-662.

Dastgheib, A., Rajabalinejad, M. R., Ranasinghe, R., \& Roelvink, D. (2012). A probabilistic approach to investigate the effect of wave chorology on process-based morphological modelling. Paper presented at the Proceedings of COPEDEC 2012, 20-24 February 2012. Retrieved from http:/doc.utwente.nl/89086/

Hemer, M., \& Griffin, D. (2010). The wave energy resource along Australia's southern margin. Journal of Renewable and Sustainable Energy, 2(4), 043108-15. doi:10.1063/1.3464753

Howorth, R., Carney, C. and Shaeri, S. (2014), The spatial distribution of sediments in the Currumbin Creek inlet, Griffith Centre for Coastal Management, Griffith University, Research Report No. 168.

Latteux, B. (1995). Techniques for long-term morphological simulation under tidal action. Marine Geology, 126(1-4), 129-141.

Lesser, G.R., Roelvink, J.A., Van Kester, J.A.T.M., Stelling, G.S. (2004), Development and validation of a three-dimensional model. Coastal Engineering, 51, 883-915.

Roelvink, J., \& Walstra, D.-J. (2004). Keeping it simple by using complex models. Advances in Hydroscience and Engineering, 6, 1-11.

Shaeri, S. (2015), Hydro-Sedimentological modelling of a jettied, narrow, tidal-inlet entrance and its associated tidal deltas (unpublished doctoral thesis), Griffith University, Gold Coast, Australia.

Shaeri, S., Tomlinson, R.B., Etemad-Shahidi, A., Strauss, D. and Hughes, L.P. (2014). Hydrodynamics of a small trained tidal inlet (Currumbin Creek, Australia), Advances in Geoscience, 39, 45-53.

Shaeri, S., Tomlinson, R.B., Etemad-Shahidi, A., Strauss, D. and Hunt, S. (2013), Field Measurement for Investigating the Dynamics of Currumbin Creek Entrances, Journal of Coastal Research, SI 65,1212-1217. 